\title{
CONFIANÇA E DESEMPENHO DE EQUIPES
}

\author{
1- João Bosco Castro Araujo* \\ Mestre em Administração pela Fundação Pedro Leopoldo (FPL), Brasil. \\ Consultor da Fundação Dom Cabral, Minas Gerais, Brasil. \\ joaoboscoaraujo@uai.com.br \\ http://lattes.cnpq.br/2678677120081326
}

\section{2- Vera L. Cançado}

Doutora em Administração CPEAD/FACE/UFMG, Minas Gerais, Brasil

Professora do Mestrado Profissional em Administração da Fundação Pedro Leopoldo (FPL), Brasil

vera.cancado@fpl.edu.br

http://lattes.cnpq.br/2160652000585374 


\title{
CONFIANÇA E DESEMPENHO DE EQUIPES
}

\section{RESUMO}

Este artigo teve como objetivo analisar como a confiança se relaciona com o desempenho de equipes. Entende-se confiança como uma relação entre duas ou mais partes, na qual há expectativa mútua do cumprimento do que foi combinado; e alto desempenho, o atingimento ou superação das metas estabelecidas. Foi realizado um estudo de caso de caráter qualitativo, em uma empresa do setor de construção civil, a partir da seleção intencional de uma equipe de alto desempenho (Equipe Alfa) e outra de baixo desempenho (Equipe Beta). A coleta de dados foi realizada por meio de análise documental, de entrevistas individuais e de observação de reunião. Os resultados indicaram que a Equipe Alfa demonstrou comportamentos relativos à confiança transacional e transformadora, encontrando-se no estágio de realização; apresenta disposição para desenvolver-se, correr riscos, inovar e melhorar; e alto desempenho em termos do atingimento das metas propostas. A Equipe Beta apresentou comportamentos mais relacionados à confiança transacional, encontrando-se no estágio de formação; apresenta disposição para consistência, compromisso e capacidade; e baixo desempenho. Esses resultados indicam que há uma relação entre a confiança transacional e transformadora e o alto desempenho em equipes.

\section{Palavras-chave}

Confiança; Confiança transformadora; Confiança transacional; Equipes de alto desempenho; Relações intraequipes.

\section{TRUST AND TEAM PERFORMANCE}

\begin{abstract}
This paper aimed to analyze the relationship between trust and teams performance. Trust is understood as a relation between two or more parties, with a mutual expectation to fulfill what was defined by the parties; and high performance is the reaching or the overcoming of the established goals. We realized a qualitative case study in a company of the civil construction sector. We intentionally selected one high performance team (Alfa team) and another low performance team (Beta team). The data collection was realized through documental analyze, individual interviews and observation of a working meeting. The results indicated that the Alfa team showed behaviors related with transactional and transformational trust finding themselves on stage of realization; they show disposition to develop themselves, to take risks, to innovate and to improve; and also they also reveal a high performance $n$ terms of the achievement of the goals. The Beta team presented behaviors related to transactional trust finding itself on the stage of formation; they show disposition for consistency, compromise and capacity; and they reveal a poor performance. These results indicate that there is a relationship between transactional and transforming trust and high performance teams.
\end{abstract}

\section{Keywords}

Trust; Transformational trust; Transactional trust; High performance team; Inter-team relationship. 


\section{Introdução}

No mundo competitivo, as empresas necessitam, cada vez mais, de equipes de alto desempenho, embora não seja comum encontrá-las, de acordo com Katzenbach (2001). Para o desenvolvimento de trabalho em equipe, uma das condições fundamentais é a existência de confiança recíproca entre seus membros. Conforme Hacker e Willard (2002), é imperativo que haja um grau elevado de confiança entre líderes e colaboradores, os quais precisam se sentir integrados na equipe para que busquem atingir os objetivos organizacionais e o desempenho esperado.

Para os fins deste estudo, entende-se confiança como uma relação entre duas ou mais partes, na qual há expectativa mútua do cumprimento do que é combinado. Ela é previsível e deriva das repetidas interações entre confiantes e confiados. Como salienta Rousseau (1998), é um estado psicológico e se baseia em expectativas positivas das intenções ou comportamentos de alguém, o que implica vulnerabilidade. Não se tem certeza de que a outra parte cumprirá o prometido, mas há uma previsão de que aconteça. A confiança, segundo Reina e Reina (2006), permeia as relações sociais e são essas relações que dão suporte para que as equipes tenham o desempenho desejado.

Embora, muitas vezes, grupo e equipe sejam tratados como sinônimos na literatura acadêmica e gerencial, a distinção entre ambos tem sido proposto por diversos autores, tais como Ivancevich (2008), Duhá (2007), Biehl (2004), Katzenbach (2001) e Marras (2000). Equipe, segundo Katzenbach (2001, p. 24), é um "pequeno número de pessoas, com habilidades complementares, comprometidas com objetivos, com metas de desempenho e abordagens comuns, pelos quais se consideram mutuamente responsáveis". Desempenho é atingimento de metas que devem ser baseadas em resultados, considerados como produtos finais ou impactos das ações, quase sempre tangíveis, que possibilitam visualizar o caminhar da equipe.

Muitas são as dificuldades quando se trata de desenvolver equipes. Entre essas, conforme apontam Katzenbach e Smith (1994), Moscovici (1985), Mandelli (2001) e Mey e Lima (2004) destacam-se: a cultura do individualismo e da independência; o modelo gerencial ainda fortemente autocrático; o tempo necessário para transformar um grupo em equipe e a exigência de urgência pelas empresas; o egocentrismo; o medo das pessoas em dar e receber feedback, baixo nível de maturidade, principalmente emocional, dos profissionais; resistência aos processos de mudança; modelos mentais inadequados.

Apesar das dificuldades, o exercício da confiança pode propiciar o trabalho em equipe. Para que uma equipe tenha alto desempenho é preciso que haja confiança entre seus membros, conforme afirmam Reina e Reina (2006). Partindo dessas considerações, delineia-se o problema de investigação deste artigo: como confiança relaciona-se com o desempenho de equipes? Estabeleceu-se como objetivo analisar como a confiança relaciona-se com o desempenho de equipes, em uma empresa do setor de construção civil. Para atingir o objetivo, foi realizado um estudo de caso de caráter qualitativo, em uma empresa do setor de construção civil, onde duas equipes foram selecionadas intencionalmente: uma de alto desempenho e uma de baixo desempenho, definido como o atingimento das metas propostas pela empresa.

Os estudos sobre confiança começaram a ganhar destaque na academia na década de 1980 , intensificando-se nos anos 1990, e chegando ao Brasil somente a partir de 2000, conforme levantamento bibliográfico realizado. Drumond (2007) afirma que somente nas duas últimas décadas, a temática da confiança passou a ocupar lugar de destaque na academia e no mercado empresarial brasileiro. Diversos estudos como os de Child (2001), Child e Rodrigues (2004), Janowicz e Noorderhaven (2002, 2009), Kraemer e Tyler (1996), Lane e Bachmann (1997), Leana e Burren (1999), Möllering (2001), Tsai e Goshal (1998), Zanini (2007), Dias (2010) confirmam a relevância do tema para o desenvolvimento e sucesso das organizações e das equipes. Este trabalho poderá contribuir para o conhecimento acadêmico, na medida em que busca relacionar confiança com equipes de alto desempenho, tema ainda pouco explorado na literatura brasileira.

Este artigo, além desta introdução, apresenta na seção 2, o referencial teórico, discutindo o conceito e a tipologia de confiança; sobre equipes, foram abordados a diferenciação entre grupo e equipe e os estágios de desenvolvimento e curva de performance de equipe. Na seção 3, a metodologia apresenta a caracterização da pesquisa, a definição da unidade de análise e de observação, as técnicas de coleta e de análise dos dados. Na seção 4, a apresentação e análise dos resultados traz informações sobre as duas equipes pesquisadas, confrontando-se os dados com a teoria; e na quinta seção, são apresentadas as considerações finais. 


\section{Referencial Teórico}

Dois são os temas centrais destacados nesta seção: confiança e equipe. Em confiança, optou-se por utilizar os conceitos de confiança transacional e transformadora (Reina \& Reina, 2006), de dependência e interdependência (Sheppard \& Sherman, 1998), de componentes e disposições necessárias para se ter credibilidade (Hacker \& Willard, 2002). Em equipe, foram abordados os conceitos de diferenciação entre grupo e equipe, e de estágios de desenvolvimento de uma equipe (Katzenbach \& Smith, 2001; Moscovici, 1985; Robbins \& Finley, 1997; Scholtes,1992).

\subsection{Confiança}

O construto confiança vem adquirindo crescente importância na literatura relacionada às ciências sociais. A compreensão do fenômeno da confiança entre pessoas, grupos ou instituições fornece material para diversas abordagens no campo da antropologia, da sociologia, da economia, da psicologia e da administração (Fukuyama, 1996; Giddens, 1991; Kramer \& Tyler, 1996; Lane, 1996; Luhmann, 1979; Tzafrir \& Harel, 2002; Zand, 1972). O termo tem significados diferentes em função dos campos abordados, sendo consequentemente as práticas de pesquisa também diferenciados. Neste estudo, optou-se pela análise das dimensões psicológica e psicossocial, centradas nas relações intraequipes. Na visão psicológica, o estudo da confiança focaliza a personalidade dos indivíduos ou um determinado grupo, segundo parâmetros situacionais e históricos. Já na visão psicossocial, a confiança manifesta-se como elemento moderador das relações entre pessoas, grupos ou empresas (Lewicki \& Bunker, 1996).

Confiança é uma relação entre duas ou mais partes, na qual há expectativa mútua do cumprimento do que foi combinado, esperando que nenhuma vá agir de maneira oportunista, seja por palavras ou ações (Novelli, 2004). Dois elementos estão implícitos nessa afirmação: familiaridade e risco. Em função da familiaridade, ou seja, do conhecimento que se tem de alguém, corre-se o risco. Familiaridade consiste em confiar na uniformidade e continuidade da conduta das pessoas. É a confiança desenvolvida no tempo e no espaço, baseada em um relacionamento de longo prazo que "substancia as credenciais que tornam cada um fidedigno aos olhos do outro", segundo Giddens (1991, p. 101). Equivale ao conceito de previsibilidade. Quando se acredita em alguém, corre-se o risco de se tornar vulnerável e de se desapontar. Confiança não significa arriscar-se, mas sim se dispor a assumir riscos; quando se confia em alguém, espera-se que ele não irá tirar vantagem (Novelli, 2004).

Confiança implica fidelidade e lealdade de alguém em cumprir uma promessa (Duluc, 2000). Ela inicia-se quando há permissão por parte de alguém em ser vulnerável, já que não se pode garantir um comportamento futuro. Se ninguém assumir o risco de confiar, o relacionamento estrutura-se pela cautela e dúvida. A maioria das relações empresariais tende a ser baseada no conhecimento que suporta a confiança. Giddens (1991) faz uma distinção entre crença (fé) e confiança. Crença se refere a uma atitude mais ou menos tida como certa de que as coisas permanecerão estáveis. Confiança pressupõe consciência do risco.

Reina e Reina (2006) desenvolveram um importante estudo sobre confiança no trabalho e concluem que uma relação de confiança está assentada em três características: a previsibilidade, que deriva das interações entre confiantes e confiados; a reciprocidade, ou o dar para receber; e a incrementalidade, que é um processo contínuo. Os autores detectaram que o processo de construção de confiança passa pelo exercício da confiança transacional, oriunda de uma transação, caracterizada como contratual, comunicativa e de competência; e da confiança transformadora, que fortalece as relações - convicção, coragem, compaixão e coletividade, conforme apresentado na Figura 1.

A confiança transacional contratual refere-se à certeza e à expectativa de que o que foi estabelecido formalmente pelas partes seja concretizado. Uma vez firmados os contratos, as partes têm a responsabilidade de cumpri-los e de promover seu acompanhamento, conforme ratificam Bennis e Nanus (1998) e Hacker e Willard (2002). Para o desenvolvimento da confiança transacional de comunicação é necessário expressar pensamentos e sentimentos, ser capaz de dar e receber feedback, sabendo, por exemplo, que não se sofrerá retaliações. Aceitação de erros contribui para desenvolver a confiança de comunicação; quando a confiança é baixa, as pessoas temem que suas informações confidenciais sejam usadas contra elas. Para desenvolver a confiança transacional relativa à competência, Reina e Reina (2006) salientam ser necessário que o líder reconheça a capacidade dos empregados, permita que tomem decisões, busque suas contribuições e os ajude a se desenvolverem. Desenvolver pessoas demonstra confiança em sua capacidade. 
Figura 1: Conceitos e componentes da confiança interpessoal no ambiente de trabalho

\begin{tabular}{|c|c|c|}
\hline \multicolumn{3}{|c|}{ TRANSACIONAL } \\
\hline Contratual & Comunicativa & Competência \\
\hline $\begin{array}{l}\text { Compreensão e cumprimento pelos } \\
\text { envolvidos sobre o que farão e o que } \\
\text { esperam um do outro }\end{array}$ & $\begin{array}{l}\text { Iniciativas voltadas para } \\
\text { compartilhamento de informações }\end{array}$ & $\begin{array}{l}\text { Respeito aos conhecimentos e às } \\
\text { habilidades do outro }\end{array}$ \\
\hline $\begin{array}{ll}- & \text { Administrar expectativas } \\
- & \text { Estabelecer fronteiras } \\
- & \text { Delegar } \\
- & \text { Encorajar o servir mútuo } \\
- & \text { Cumprir acordos } \\
- & \text { Comportar-se consistentemente }\end{array}$ & $\begin{array}{ll} & \text { Compartilhar informação } \\
\text { - } & \text { Dizer a verdade } \\
\text { - } & \text { Admitir erros } \\
\text { - } & \text { Dar e receber feedback } \\
\text { - } & \text { Manter confidencialidade } \\
\text { - } & \text { Falar com bons propósitos }\end{array}$ & $\begin{array}{ll}- & \text { Respeitar o conhecimento e } \\
& \text { habilidades das pessoas } \\
\text { - } & \text { Permitir que tomem decisões } \\
\text { - } & \text { Envolver as pessoas e buscar } \\
& \text { suas contribuiçòes } \\
\text { - } & \text { Ajudá-las a se desenvolver }\end{array}$ \\
\hline
\end{tabular}

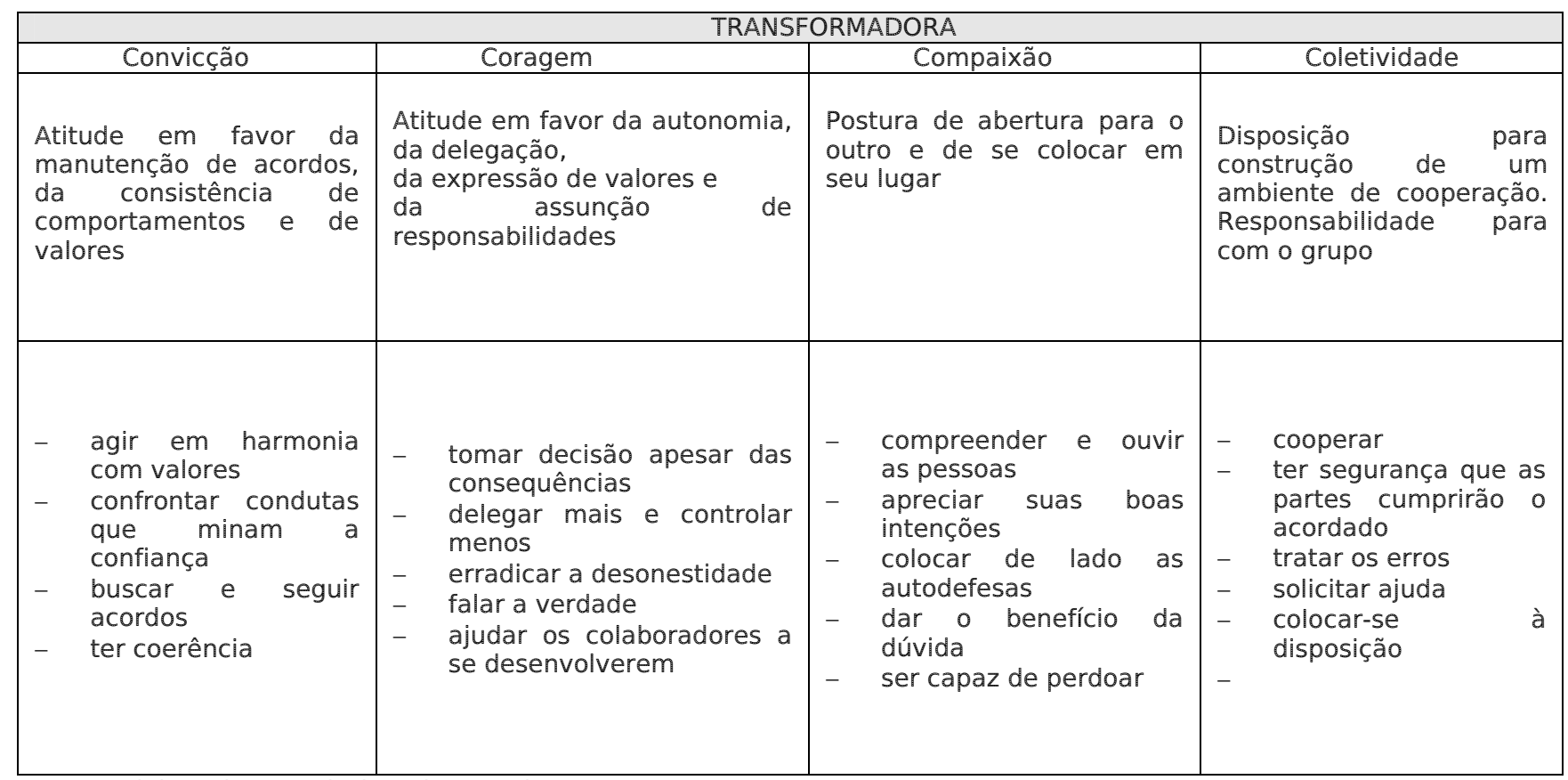

Fonte: Elaborado a partir de Reina e Reina, 2006.

A prática dos comportamentos inerentes à confiança transacional incrementa a confiança transformadora. A construção de uma confiança sustentável, contudo, se faz mediante a utilização dos fatores da confiança transformadora que, segundo Reina e Reina (2006) são: convicção, coragem, compaixão e coletividade. A convicção manifesta-se quando as pessoas agem em harmonia com seus valores, confrontam condutas que minam a confiança, buscam e seguem os acordos e têm coerência. As convicções têm origem na consciência de altos propósitos. De acordo com Comte-Sponville (1995, p. 66), coragem é a capacidade de superar o medo e implica "harmonizar os riscos que se corre e o fim que se tem em vista". Para Reina e Reina (2006) ter coragem é tomar uma decisão apesar das consequências, delegar mais e controlar menos, erradicar a desonestidade das condutas, falar a verdade, ajudar seus colaboradores a se desenvolverem, etc. Para Hacker e Willard (2002), é se dispor a correr riscos. Ter compaixão significa compreender as pessoas, ouvi-las, colocar de lado as autodefesas, dar o benefício da dúvida, ser capaz de perdoar, dentre outros. Compaixão é considerar os sentimentos do outro, é ser receptivo às suas necessidades, escutar empaticamente e exercitar o companheirismo e solidariedade (Comte-Sponville, 1995; Robbins \& Finley, 1997). O último fator da confiança transformadora é a coletividade ou responsabilidade para com o grupo. A visão e a atuação sistêmica são as bases desse fator, estando implícito que o todo e a consciência da ação (ou da não ação) de cada um impacta esse todo. Ter visão de coletividade é verificar como cada um pode contribuir para esse todo.

Outro estudo sobre confiança foi desenvolvido por Sheppard e Sherman (1998). Os autores afirmam que quatro formas relacionais servem como blocos estruturais para construção dos relacionamentos, seja entre indivíduos, empresas ou nações. São elas: de dependência superficial, de dependência profunda, de 
interdependência superficial e de interdependência profunda. A proposta de Sheppard e Sherman (1998) mostra que quanto maior o nível do risco, maior é o da confiança exigida.

A dependência superficial existe quando os resultados de uma parte dependem da outra. Ela envolve dois tipos de riscos para o confiante: a inconfiabilidade, ou a possibilidade de que a outra parte não seja confiável, que não se comporte da forma esperada; e a indiscrição, a possibilidade de que ela compartilhe informações que não se devem compartilhar. A dependência profunda ocorre, por exemplo, nos relacionamentos dos subordinados com seus líderes formais ou quando uma parte pode tomar uma decisão sobre a qual a outra não tem ou tem pouca possibilidade de interferência por falta ou assimetria do conhecimento. Algumas formas de risco podem ocorrer nessas situações: a trapaça, o abuso, a negligência e o dano à autoestima da parte que se sente prejudicada. A interdependência superficial ocorre quando as partes envolvidas administram eficientemente seus comportamentos para alcançar as metas. A reciprocidade ocorre naturalmente. Observa-se essa forma relacional nos relacionamentos de equivalência, com pares ou colegas. O aumento da intimidade propicia relações mais interdependentes. O risco é o de coordenação deficiente. A interdependência profunda ocorre quando as partes fornecem as informações necessárias à outra e interagem, visando alcançar as metas estabelecidas. Em algumas situações, contudo, não é possível a comunicação regular e completa, possibilitando o risco de erro de previsão. Por falta de informações, uma das partes pode não prever as intenções e ações da outra (Sheppard; Sherman, 1998).

Hacker e Willard (2002) complementam a abordagem anterior e consideram que a confiança seja a disposição de uma pessoa para aceitar e/ou aumentar sua vulnerabilidade com relação à outra, baseada na sua percepção da capacidade, compromisso e consistência dessa pessoa. Pesquisa realizada pelos autores detectou seis componentes necessários para construção de uma relação de confiança: os três primeiros (consistência, compromisso e capacidade) compõem a confiabilidade; os outros três (praticar disposições para investir, analisar posicionamentos e correr riscos) compõem a disposição para confiar. A consistência está relacionada com a sintonia entre palavras e ações e com a continuidade do comportamento. $O$ compromisso existe quando há manifestação de aderência das pessoas aos objetivos comuns, quando ocorrem decisões conjuntas e consideração pelo outro. A capacidade se refere às competências para atender as demandas de desempenho. Quanto mais abundantes forem estes componentes, maior o nível de confiança, afirmam os autores. Uma pessoa é merecedora de confiança quando é consistente, compromissada e capaz. Uma pessoa está disposta a confiar quando investe tempo e energia, analisa os posicionamentos e corre riscos. Os três primeiros se associam para formar a confiabilidade de uma pessoa, ou seja, o quanto ela é merecedora de confiança. Os outros três associam-se para formar a disposição de alguém para confiar, ou seja, quanto ela está disposta a entrar ou estar em relações confiantes.

O exercício da confiança interpessoal permite o trabalho em equipes: "Sem confiança, as relações de trabalho não prosperarão e as empresas não utilizarão ou superarão seu potencial", enfatizam Reina e Reina (2006, p. 10). A opção por trabalhar em equipe implica acreditar e criar mecanismos de confiança, como afirmam Katzenbach e Smith (1994). Quando não há confiança, é impossível uma equipe se desenvolver, aponta Kotter (1997).

\subsection{Trabalho em Equipe e Desempenho}

Embora, muitas vezes, grupo e equipe sejam tratados como sinônimos, principalmente na literatura gerencial, existem diferenças nos conceitos, conforme apontado por Ivancevich (2008), Duhá (2007), Biehl (2004) e Marras (2000). Segundo Katzenbach e Smith (1994), em um grupo, as responsabilidades são assumidas individualmente. Os grupos interagem, basicamente, para compartilhar informações, conhecimentos e tomar decisões e não se engajam em um trabalho conjunto. Não existe uma sinergia positiva que crie um desempenho maior do que a soma das entradas. Já a equipe requer responsabilidade individual e mútua e, geralmente, obtém um resultado superior àquele que seus participantes teriam individualmente. Uma equipe de trabalho gera uma sinergia, que possibilita a empresa aumentar seus resultados, sem precisar aumentar as entradas. Equipe é um grupo desenvolvido, e um grupo se desenvolve quando passa a prestar atenção à sua forma de agir e busca resolver os problemas que afetam seu funcionamento Desenvolver um grupo é ajudá-lo a institucionalizar um processo constante de autoanálise (Moscovici, 1985). A evolução de grupo para equipe, segundo Schein (1977), implica em uma compreensão das pessoas, de suas percepções e experiências e de suas relações formais e informais.

O caminhar de um grupo rumo a uma equipe pode ser sistematizado. Para se tornarem bemsucedidas, as equipes passam por quatro estágios, conforme identificou Scholtes (1992), baseado no 
trabalho pioneiro de Tuckman, desenvolvido nos anos de 1970. O primeiro estágio - a formação - é o momento inicial, quando cada um está aprendendo a lidar com o outro; caracteriza-se pelo conhecimento mútuo, criação de alianças temporárias, alinhamento de metas, construção das condutas norteadoras da ação da equipe, definição de papéis e início de uma relação de confiança. É uma transição da condição de indivíduo para a de membro. Passado esse estágio inicial de convivência, as pessoas começar a mostrar o que pensam e sentem. É o início do estágio da tormenta ou turbulência: as emoções emergem, os conflitos são explicitados, buscando suas soluções. A turbulência pode vir na forma de resistência à tarefa e às abordagens do processo que diferem do habitual. No final desse estágio ocorre um realinhamento de metas, papéis e regras de conduta. Nesses dois primeiros estágios, a produtividade é baixa. Inicia-se, então, o estágio da aquiescência ou normalização, quando as informações são compartilhadas, ocorre um novo alinhamento de metas e as relações, anteriormente competitivas, tornam-se mais cooperativas. Esse estágio compreende o sentimento de alívio, porque parece que tudo vai funcionar e a harmonia e a alegria surgem. A equipe já apresenta desempenho significativo. Ao chegar ao estágio de realização ou atuação, as equipes manifestam características como: atendimento às expectativas mútuas, compreensão dos pontos fortes e fracos uns dos outros, papéis clarificados, análise contínua do desempenho individual e grupal e um alto grau de confiança mútua. O desempenho é alto, a competência interpessoal é elevada e há satisfação pelo progresso, a equipe é coesa e eficaz (Robbins \& Finley, 1997; Scholtes, 1992).

Esse processo de desenvolvimento das equipes é tratado por Katzenbach e Smith (1994) de forma similar. Analisando duas variáveis - potencial de performance e eficácia da equipe - eles elaboraram um diagrama, denominado curva de performance da equipe: potencial de performance se relaciona com resultados, e eficácia da equipe com sua dinâmica e interação, conforme Figura 2:

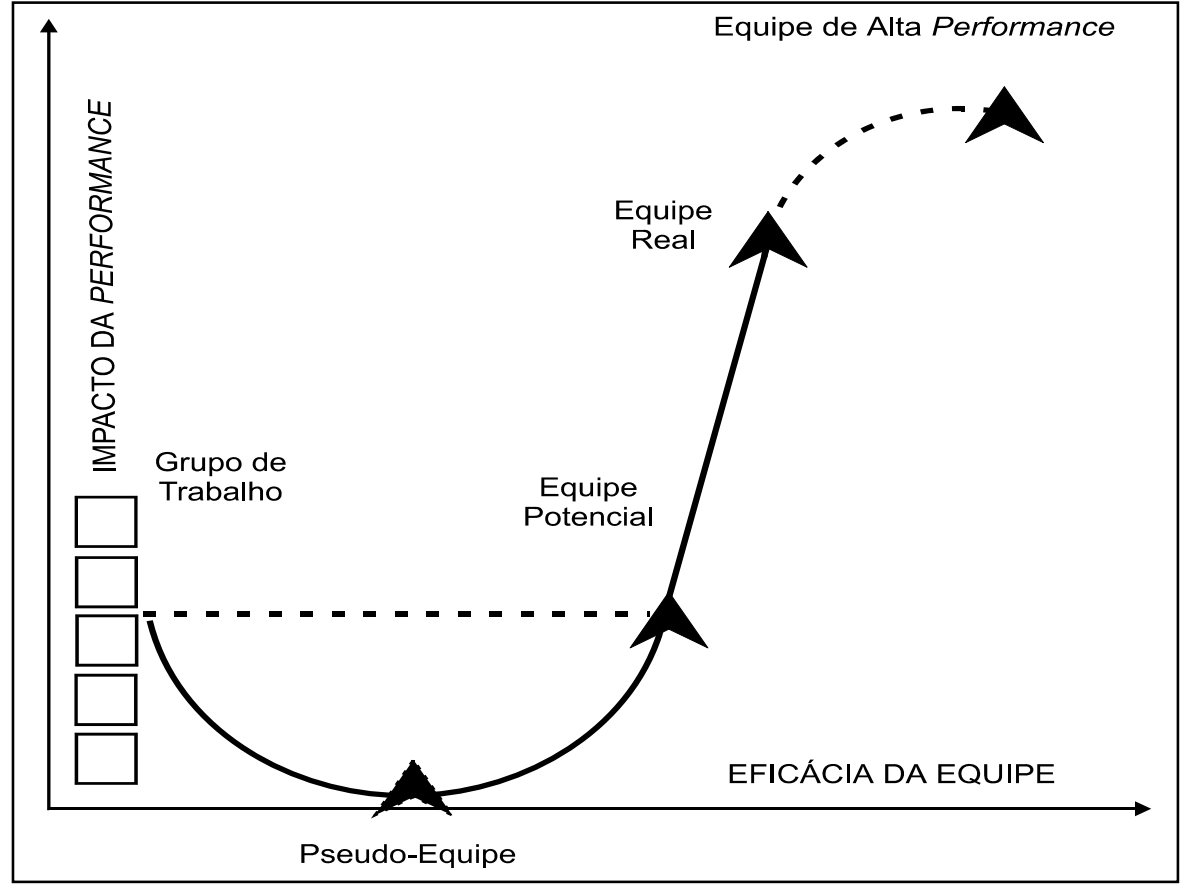

Figura 2: Curva de performance de uma equipe.

Fonte: Katzenbach e Smith, 1994, p. 84.

No início da curva - grupo de trabalho - a interação entre os membros do grupo visa, basicamente, compartilhar informações, práticas ou decisões, focando o desempenho individual em sua área de responsabilidade; equivale à etapa de formação. No segundo ponto da curva - a pseudoequipe - há um esforça para se tornar uma equipe, mas não se visa melhorar ou construir propósitos e metas de desempenho comuns; equivale à etapa de tormenta. A equipe potencial é o terceiro ponto: verifica-se uma necessidade de um desempenho incremental e sua busca. Os membros empenham-se em clarificar objetivos, metas e abordagens de trabalhos comuns, mas ainda não há o senso de responsabilidade coletiva. Equivale à etapa de aquiescência. O próximo ponto é a equipe real: "um pequeno grupo de pessoas, com conhecimentos complementares, compromissadas com propósitos, metas e abordagem de trabalhos comuns, pelos quais se consideram mutuamente responsáveis" (Katzenbach \& Smith, 2001, p. 42). No ápice da curva, encontra-se a equipe de alta performance, que, além de satisfazer todas as condições da equipe real, possui participantes compromissados com o crescimento uns dos outros, 
apresenta níveis de desempenho significativamente acima daqueles da equipe real em semelhante situação e atendem as expectativas de seus participantes. Equivalem à fase de realização.

Interligando-se os estágios de desenvolvimento e os níveis de desempenho de uma equipe com os conceitos de confiança transacional e transformadora, tornou-se possível elaborar a Figura 3, na qual se evidencia que o desenvolvimento das equipes está relacionado com os níveis de confiança e de desempenho.

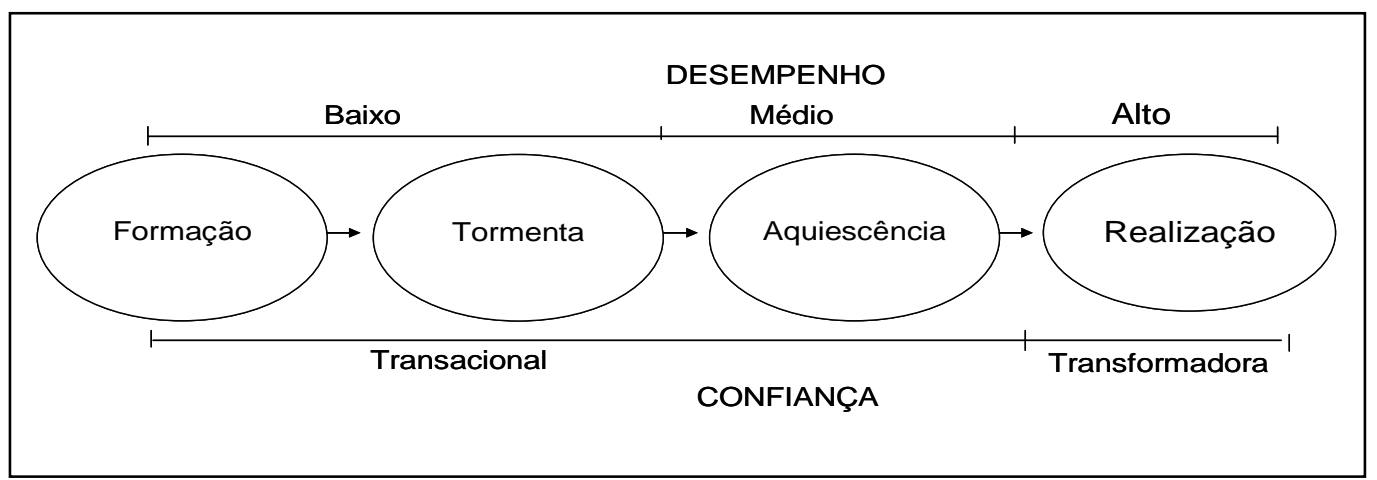

Figura 3: Estágios de desenvolvimento de equipe, confiança e desempenho.

Fonte: Elaborada pelos autores

Existem muitas abordagens sobre equipes além dos autores aqui citados, mas tomou-se como central o referencial de Katzenbach e Smith (2001), com aporte de autores como Scholtes (1992) e Robbins e Finley (1997). Essa escolha se deu em função da consistência das abordagens, de seu caráter sistêmico e pela sua instrumentalização, compatível com os objetivos delineados para a pesquisa empírica.

\section{Metodologia}

Para a realização da pesquisa, optou-se por utilizar a estratégia de estudo de caso, de caráter descritivo e explicativo. Conforme Yin (2005), o estudo de caso busca examinar o fenômeno contemporâneo em seu contexto real, caracterizando-se por um estudo profundo e exaustivo, que permite o amplo e detalhado conhecimento de determinado objeto ou fato.

A partir do referencial teórico, foi elaborada a Figura 4. Esse quadro apresenta os conceitos de confiança (nas colunas 1, 2 e 3), o conceito de estágios do desenvolvimento de equipes (coluna 4) e o conceito dos níveis de desempenho de equipes (coluna 5). As duas linhas do quadro mostram as duas direções em que esses conceitos foram abordados e os pontos de diálogo entre esses conceitos, os quais orientaram a coleta de dados e a análise dos resultados dessa pesquisa.

\begin{tabular}{|c|c|c|c|c|}
\hline $\begin{array}{l}\text { (1) } \\
\text { Reina e Reina } \\
(2002)\end{array}$ & $\begin{array}{l}\text { (2) } \\
\text { Sheppard e Sherman } \\
\text { (1998) }\end{array}$ & $\begin{array}{l}\begin{array}{l}(3) \\
\text { Hacker e Willard } \\
(2002)\end{array} \text {, } \\
\text { (202) }\end{array}$ & $\begin{array}{l}\text { (4) } \\
\text { Scholtes (1992) }\end{array}$ & $\begin{array}{l}\text { (5) } \\
\text { Katzenbach e Smith } \\
(2001)\end{array}$ \\
\hline $\begin{array}{l}\text { Confiança } \\
\text { Transformadora }\end{array}$ & $\begin{array}{l}\text { Interdependência } \\
\text { profunda }\end{array}$ & $\begin{array}{l}\text { Disposição para: } \\
\text { Investimento } \\
\text { Análise } \\
\text { posições } \\
\text { Correr riscos }\end{array}$ & Realização (atuação) & $\begin{array}{l}\text { Equipe de alta } \\
\text { performance } \\
\text { Equipe real }\end{array}$ \\
\hline $\begin{array}{l}\text { Confiança } \\
\text { Transacional }\end{array}$ & $\begin{array}{l}\text { Interdependência } \\
\text { superficial } \\
\text { Dependência profunda } \\
\text { Dependência superficial }\end{array}$ & $\begin{array}{l}\text { Componentes: } \\
\text { Consistência } \\
\text { Compromisso } \\
\text { Capacidade }\end{array}$ & $\begin{array}{l}\text { Aquiescência } \\
\text { (normatização) } \\
\text { Tormenta (turbulência) } \\
\text { Formação }\end{array}$ & $\begin{array}{l}\text { Equipe potencial } \\
\text { Pseudo-equipe } \\
\text { Grupo de trabalho }\end{array}$ \\
\hline
\end{tabular}

Figura 4: Relação entre confiança e desenvolvimento de uma equipe.

Fonte: Elaborado pelos autores

Visando a realização da pesquisa, foi selecionada uma empresa do setor de construção civil, aqui denominada Tessália, para resguardar sua identificação. Sua escolha, além da acessibilidade (Vergara, 2004), se deu pelo fato de ser uma empresa de engenharia que trabalha por projetos, nos quais são alocadas equipes multidisciplinares, constituindo, portanto, foro privilegiado para a análise da confiança e seu impacto em equipes de alto desempenho. 
A unidade de observação foram duas equipes: uma de alto desempenho (denominada Alfa) e outra de menor desempenho (Beta), selecionadas em função do atingimento ou superação das metas definidas pela empresa. A indicação das equipes participantes da pesquisa foi feita pelo Presidente e pelo Gerente de Administração, em conjunto com o pesquisador. Para escolha dessas equipes foram utilizados três critérios: nível organizacional, número de participantes e tempo de relacionamento. As equipes selecionadas eram do mesmo nível organizacional, possuíam um número aproximado de integrantes (Alfa: seis e Beta: cinco) e o mesmo tempo de funcionamento, de, aproximadamente, um ano e oito meses.

Foram utilizadas três técnicas de coleta de dados: análise documental, entrevistas e observação não participante. Inicialmente, foram coletados dados em documentos e site da empresa, notícias na Internet, nas atas de reunião e no resultado da pesquisa de satisfação dos clientes. Foram realizadas 18 entrevistas semiestruturadas individuais, seguindo-se roteiro baseado no modelo de pesquisa: 15 entrevistas individuais, com todos os integrantes de cada equipe, designados por letras do alfabeto; uma com o Presidente da empresa; e duas com o Gerente de Administração (responsável pelo RH, Planejamento e Controle). Foi realizada pelo pesquisador a observação de uma reunião de uma das equipes, que registrou as principais informações em um diário de campo, seguindo o modelo de pesquisa proposto. A outra equipe não realizava reuniões sistematizadas, apenas encontros informais para troca de informações tecnooperacionais.

O cruzamento de dados de fontes diversas (registros, entrevistas com membros da equipe e com gestores e observação de reunião) visou aumentar a confiabilidade dos dados (Collis \& Hussey, 2005; Yin, 2005). Alguns princípios, conforme enfatiza Yin (2005), são importantes para o trabalho de coleta de dados na realização dos estudos de caso: utilização de várias fontes de evidência, criação de um banco de dados e sustentação de um encadeamento de evidências. Yin (2005, p. 111) ainda acrescenta (...) "Estes princípios são extremamente importantes para realizar estudo de casos de alta qualidade e (...) ajudarão o pesquisador a tratar dos problemas de validade do constructo e de confiabilidade". Tais princípios nortearam a coleta e a análise dos de dados.

A análise dos dados se deu pelo método de construção da explanação, conforme proposto por Yin (2005). Utilizando-se da confrontação das diversas fontes de informação entre si e com a teoria, buscou-se construir uma explanação para o fenônemo pesquisado: comparou-se os eventos empiricamente observados com os teoricamente previstos (Yin, 2005). Os dados coletados na análise documental, na reunião e nas entrevistas realizadas foram compilados em formulários específicos, comparando-se os resultados da equipe de alto desempenho com os da equipe de menor desempenho. Esses dados foram confrontados com o referencial teórico de forma a responder o problema de investigação.

\section{Apresentação e Análise dos Resultados}

A Tessália (nome fictício), empresa foco do estudo de caso apresentado neste artigo, atua desde a década de 1930, figurando na lista das mais bem sucedidas do setor de construção civil industrial do país. O atual Presidente vem promovendo uma série de mudanças na empresa, sendo um dos destaques o fortalecimento do trabalho em equipe. Apesar de seu estilo de liderança predominantemente diretivo, ele vem promovendo um conjunto de encontros gerenciais para desenvolver seu pessoal, principalmente no que se refere ao trabalho em equipe. Segundo ele, a autonomia das equipes vai sendo aumentada à medida que elas atingem os resultados esperados.

As equipes de trabalho são formadas para atender à demanda de obras de empresas contratantes. 0 processo da obra inicia-se com a elaboração do projeto, feito ou encomendado pela Contratante e com a sua orçamentação. Caso ganhe a concorrência, inicia-se a mobilização da equipe. Nessa etapa, a Diretoria escolhe o gerente de contrato e a equipe, sendo que o gerente opina sobre a formação da equipe, de acordo com a disponibilidade dos profissionais. Observou-se que há uma tendência em trabalhar com alguém com quem já se tenha trabalhado anteriormente e em que se confie: engenheiros e gerentes de contrato seguravam, por exemplo, encarregados de um contrato que estava terminando, para que eles não fossem para outra obra. A obra é então implantada, de acordo com os cronogramas de execução e controle. Terminada a obra, ocorre a desmobilização da equipe.

As equipes selecionadas para esta pesquisa foram denominadas de Alfa e Beta. A equipe Alfa era composta por seis integrantes: gerente de contrato $(A A)$, dois engenheiros de produção $(A B$ e $A C)$, chefe administrativo ( $A D)$, gerente de medição $(A E)$ e gerente de planejamento ( $A F)$. O seu cliente é uma grande 
empresa do setor siderúrgico. A equipe Alfa passou por três momentos distintos, tendo-se como parâmetro a mudança dos gerentes de contrato. O foco de análise desta pesquisa foi o momento 3 , que iniciou-se com a designação do gerente $\mathrm{AA}$, com mais experiência em obras de grande vulto que permaneceu até o término das obras: um ano e seis meses. Esse gerente provocou uma série de reformulações, tanto operacionais quanto na dinâmica interpessoal. Além de promover reuniões para ajustar responsabilidades e tarefas, abriu espaço para a expressão dos sentimentos, percepções e dificuldades de interface entre os integrantes da equipe. Essas ações implantadas foram acompanhadas de perto por ele.

A equipe Beta era composta por cinco integrantes: gerente de contrato (BA), gerente de planejamento e de medição (BB), chefe administrativo ( $B C$ ), gerente de produção (BD) e engenheiro de segurança $(B E)$. Seu cliente era uma grande empresa do setor de mineração. A duração das obras estava planejada para um ano e sete meses. A equipe Beta passou por dois momentos. No momento 1 , havia um desentendimento entre os profissionais da equipe - BA e BD se davam bem, mas não tinham uma boa relação com o gerente $\mathrm{BF}$, já deligado do projeto, o que acabou por emperrar o processo. De acordo com as informações dos entrevistados, os conflitos eram percebidos, mas não resolvidos, pois não se conversava a respeito. Problemas operacionais foram detectados e a equipe não conseguiu administrá-los. Essa situação de desajuste da equipe permaneceu durante sete meses, acarretando problemas no cumprimento do contrato, com atraso no cronograma previsto. No momento 2, o então responsável pelo planejamento (gerente BB) conversou com o presidente da Tessália, solicitando a troca do gerente e a vinda do gerente BA, com o qual trabalhara no contrato anterior. Segundo ele, "os três se complementavam em tudo e era disso que a equipe estava precisando". Com essa alteração, ocorreram algumas pequenas melhorias, mas os problemas operacionais e de interação entre o grupo foram se avolumando. Essa equipe ficou até o término das obras e foi o alvo desta pesquisa.

Além desses problemas, várias situações adversas ocorreram nessa obra: atraso nos serviços de terraplanagem, chuvas intensas, demora na entrega dos projetos pela contratante, soluções inadequadas de engenharia, gestão inadequada do cliente. Esse conjunto de situações dificultou a implementação dos serviços, tornando esse contrato deficitário para a Tessália. Segundo o presidente, além dessas situações imprevistas, faltou uma coesão na equipe para que conseguissem produzir sob pressão e tensão. "Apesar das circunstâncias, a equipe poderia produzir mais do que está fazendo (...) falta ação, produtividade compatível com este desafio", ressaltou o Presidente.

Analisando-se a confiança transacional contratual (Reina \& Reina, 2006), na equipe Alfa existiam definições sobre o processo de trabalho que eram conhecidas e respeitadas por todos. Um exemplo dessa relação pôde ser observado na reunião semanal realizada pela equipe. Observou-se que cada participante sabia o que se esperava dele, a pauta foi seguida com assertividade, os horários cumpridos, o tempo bem administrado, os registros feitos e os objetivos buscados com afinco.

$\mathrm{Na}$ equipe Beta ficaram pouco evidenciados os comportamentos que indicassem a existência da confiança transacional contratual. Observou-se descompasso dos envolvidos no estabelecimento de uma forma conjunta de trabalhar e a Diretoria teve que intervir. Também foram observadas promessas não cumpridas denotando, inclusive, inconsistência, conforme declarações do gerente BF:

Nós três não estávamos conseguindo atender a contento nosso cliente. A Diretoria, então, decidiu que cada um de nós teria atribuições específicas. Acreditei que, cada um fazendo seu papel, as coisas iriam se encaixar. Mas ficou um comando de três cabeças. O cliente cobrava dos três. Faltava unidade de comando (...). Para não ficar mal com o cliente, se planejava algo que a equipe não daria conta. A cobrança vinha em cima de mim. Ainda hoje, continuam prometendo o que não vão cumprir (Entrevista BF).

Em relação à confiança transacional de comunicação, pôde-se observar que a equipe Alfa tinha uma dinâmica de comunicação formal estabelecida. Todos os dias, a equipe reunia-se três vezes: no café da manhã, que ocorria no local de trabalho, próximo ao horário de almoço e à tarde. Às segundas-feiras, eram realizadas reuniões de rotina, com registro oficial dos compromissos em ata. Na observação de uma reunião da equipe, o pesquisador verificou que os participantes tiveram liberdade de participação, solicitaram esclarecimentos, fizeram comentários e proposições sobre os problemas e as possíveis decisões. O líder (gerente BA) respeitou e utilizou as contribuições. Ao final, ele se posicionou e informou as ações a serem implementadas, com os prazos respectivos e quem eram os responsáveis, definindo e delegando tarefas. Observou-se no grupo uma dinâmica de condução de trabalho com foco nos resultados, em um clima da descontração, alegria, informalidade e de brincadeiras. O líder da Alfa fez algumas considerações que retratam o comportamento da equipe: 
Fazemos reuniões quase todos os dias. O modelo de gestão é horizontal, mas com dono. Todos sabem das responsabilidades. (...) Passo $99,0 \%$ as informações. Se ela é vazada, tenho certeza que da equipe não sai. Tudo que eu sei, dois integrantes da equipe sabem. Toda informação, a princípio, tem que ser disseminada. É importante, entretanto, saber passar as informações corretas para as pessoas corretas. (...) Escutamos todas as ideias, mesmo as mais absurdas. Pergunto, por exemplo, a um pedreiro, como as coisas estão indo e o que poderia ser feito para melhorar. E aprendemos a elogiar. Nunca ache que você sabe tudo (...) A verdade é dita, doa a quem doer (...) O erro é usado como aprendizagem. Nós erramos (Entrevista BA).

Como se pôde observar, a comunicação era tratada como algo prioritário pela equipe. Compartilhar as informações, falar a verdade, dar e receber feedback, agir com bons propósitos são comportamentos característicos de confiança transacional de comunicação (Reina \& Reina, 2006).

Já na Equipe Beta, observou-se divergência de opiniões quanto a realização de reuniões. O pesquisador observou que não foram realizadas reuniões sistematizadas, durante o período da pesquisa. Entretanto, o participante $\mathrm{BC}$ afirmou que "há reuniões toda terça-feira, às 18 horas, com duração de 1 hora e geralmente tem pauta, que é falada na hora pelo gerente". Já BE declarou que "As reuniões existem para resolver problemas de urgência e das quais eu não participo". "Começamos a fazer às terças-feiras, mensalmente, por volta do dia 20, para fechamento e planejamento do mês" (BD). Nessas reuniões mensais, não havia formalização em atas. O registro ficava na agenda de cada um, afirmou BA. Um dos membros da equipe (BD) afirmou que não gostava de reuniões. Apesar de o pesquisador ter solicitado que fosse informado quando ocorresse uma reunião para que pudesse observá-la, durante 40 dias, nenhuma reunião formal aconteceu. Observou-se que ocorriam, na realidade, encontros informais entre o gerente (BA) e o responsável pela produção (BD), não havendo envolvimento da equipe inteira. Poucas reuniões eram realizadas, gerando desnível de informação. Como meios de comunicação, existia um quadro para anotações na sala de BA e BD, no qual cada um anotava o que precisava do outro. Quando decisões rápidas precisavam ser tomadas, a comunicação era realizada por e-mail, conforme afirmou BA. Os problemas de relacionamento não eram conversados.

Compartilhar informações, falar a verdade, admitir erros, dar e receber feedback, agir com bons propósitos são comportamentos característicos da confiança de comunicação (Reina \& Reina, 2006). Esses comportamentos não foram evidenciados nessa equipe.

Em relação à confiança transacional de competência, observou-se que na Equipe Alfa, as negociações com o cliente nas frentes de trabalho eram realizadas pelo integrante da equipe que tivesse melhor contato e mais habilidade. A competência e as características pessoais definiam as regras e as ações. O Gerente AA disse:

Para cada negociação, estabelecemos uma estratégia e quem vai e, quando esta não está montada, adia-se a reunião. Nas reuniões com os clientes, sempre vamos dois ou três: um soma ao outro. No contato com a Contratante, inclusive, um profissional com uma boa relação com a mesma, que ajuda a equipe em suas dificuldades de interação com a mesma. A equipe participa dessa interação.

Os participantes da equipe Alfa mostraram que conheciam sua competência e responsabilidades, tinham autonomia para resolver os problemas, podendo ou não informar ao seu superior, dependendo do grau de relevância e de impacto nos resultados, conforme afirmou AA. O líder direcionou as decisões para pessoas específicas, considerou o conhecimento técnico dos integrantes, envolvendo-os e buscando suas contribuições. Permitiu os participantes questionarem, darem sugestões e tomarem decisões. A competência dessa equipe era reconhecida pela empresa, conforme declarações do presidente.

Já na Equipe Beta, a maior parte das declarações sobre a competência girou sobre os pontos fracos de cada um: Fulano é acomodado, sicrano não está comprometido, beltrano é pouco proativo, etc. Conforme declarações de BD, não ocorriam troca de experiências na equipe: “Não tiramos proveito da equipe: ela está aquém de sua capacidade". A não utilização dos conhecimentos e habilidades dos empregados, conforme afirmam Reina e Reina (2006), fez com que eles não se sentissem merecedores de confiança e não assumissem mais responsabilidades.

Pode-se concluir, pelos fatos expostos, que na equipe Beta, os comportamentos inerentes à confiança transacional estão presentes, apesar dos problemas detectados. O descompasso dos envolvidos no estabelecimento de uma forma conjunta de trabalhar, a inconsistência, o não compartilhamento de informações entre os integrantes, não admitir erros, não dar e receber feedback e a não utilização dos conhecimentos e habilidades dos empregados, dificultou a relação entre os integrantes da equipe. Ao contrário, na equipe Alfa, os elementos da confiança transacional deram base para que a relação evoluísse 
para a confiança transformadora. $\mathrm{O}$ trabalho da equipe era baseado no dar para receber, em um ambiente de trabalho seguro e produtivo, no qual as relações nutrem-se e o desempenho aumenta, conforme ressaltado por Reina e Reina (2006).

Em relação à confiança transformadora (Reina \& Reina, 2006), os integrantes da equipe Alfa manifestaram em vários momentos postura e comportamentos que evidenciavam convicção. A existência, por exemplo, de valores comuns era expressa por alguns integrantes da equipe. $O$ gerente de contrato AA foi enfático quando disse "Confiança está ligada à honestidade". "Honestidade, transparência e sinceridade fazem parte de nosso modo de ser", afirmou AC. Observou-se que esses princípios e os acordos estabelecidos transformavam-se em um código de conduta que era cumprido, estando explicitados nos outros fatores da confiança transformadora - coragem, compaixão e coletividade.

Coragem refere-se a atitude em prol da delegação, da autonomia e da assunção de responsabilidades, segundo Reina e Reina (2006). Esse comportamento ficou evidenciado na Equipe Alfa: nas tomadas as decisões, as responsabilidades eram naturalmente assumidas pelos responsáveis. Um comportamento característico da compaixão é acreditar que as pessoas são, por princípio, íntegras. 0 gerente AA assim se posicionou: "Confio nas pessoas até que me provem o contrário". Conhecer e considerar o outro é também um comportamento característico. O conhecimento mútuo é grande pelo fato de morarem e trabalharem juntos, mas, sobretudo, pela abertura ao diálogo e à interação. Já a coletividade refere-se à disposição para construção de um ambiente de cooperação e está relacionada com a responsabilidade para com o grupo. A cooperação estava presente e foi manifestada nas afirmações expressas na entrevista: "Aqui temos uma grande amizade e é a principal característica desta equipe" (AC). "Nossa união, só quem vive nela entende. Trabalhamos em conjunto com honestidade e respeito às pessoas" (AB). A responsabilidade para com o grupo foi percebida quando os compromissos individuais eram rigorosamente cumpridos, gerando prestação de contas nas reuniões que aconteciam frequentemente.

Já na Equipe Beta, não se verificou a construção da relação de confiança transformadora. O líder da equipe centralizava as decisões. A equipe não se reunia para resolver os problemas operacionais e muito menos os humanos. As dificuldades de interação não eram conversadas e resolvidas. BA, BD e BF explicitaram que nenhum deles sequer apontava problemas de relacionamento (coragem). A consideração pelo outro, a abertura e respeito mútuo (compaixão) não foram comportamentos observados. A disposição para construção de um ambiente de cooperação (coletividade) não foi demonstrada. Por exemplo, as responsabilidades eram assumidas individualmente e não um compromisso do grupo. BD comentou que o grupo não possuía entrosamento. Havia uma interação entre BA e BD, o gerente do contrato e o responsável pela produção, que se tratavam como "quase irmãos". De maneira geral, ficaram pouco evidenciadas na equipe Beta, atitudes, posturas ou disposições significativas relativas aos fatores da confiança transformadora (Reina \& Reina, 2006).

Esses dados demonstram o quanto a equipe Alfa manifestou comportamentos de confiança transformadora, fato pouco evidenciado na equipe Beta. Essa diferença merece destaque, uma vez que a confiança transformadora é possibilidade pela manifestação da confiança transacional e a equipe Beta já indicava não possuir esse suporte de alavancagem.

A partir da análise dos dados baseada nas formas relacionais de confiança propostas por Sheppard e Sherman (1998), pôde-se perceber que a equipe Alfa estava em uma relação de interdependência profunda, com condutas positivas em todas as outras formas, enquanto que a equipe Beta estava em uma relação entre dependência superficial e dependência profunda, apresentando condutas inadequadas nas outras formas. Na equipe Alfa, percebeu-se a utilização maior dos conhecimentos e habilidades e maior responsabilidade perante os compromissos, assim como uma cultura de compartilhamento de informações. $\mathrm{Na}$ equipe Beta, percebeu-se uma centralização de decisões e pouca disseminação de informações. Mecanismos não foram utilizados para incitar um comportamento confiável, tais como reuniões e o exercício mais amiúde da delegação. Honestidade, integridade, altruísmo e afetividade - fatores indicados Sheppard e Sherman (1998) nas relações de interdependência - foram notados somente na equipe Alfa. Percebeu-se uma intimidade, reciprocidade e uma coordenação mais efetiva, indicando a interdependência superficial. Já a equipe Beta, observou-se que a ausência de um sistema de informação e dificuldade de coordenação das ações. Os comportamentos interdependência profunda foram observados na equipe Alfa os integrantes da equipe forneciam informações necessárias e interagiam, buscando alcançar as metas estabelecidas. Na equipe Beta não foram percebidos mecanismos formais para compartilhamento de 
informações que suportassem a equipe para atingimento das metas, a não ser um quadro nas salas de BA e BD que servia para informes entre eles. Problemas relacionais não eram conversados.

Nesta pesquisa, também se buscou analisar a presença dos seis ingredientes necessários para construção de uma relação de confiança, propostos por Hacker e Willard (2002): os três elementos de confiabilidade (consistência, compromisso e capacidade) e as de três disposições para a prática da confiança (dedicação de tempo e energia, disposição para correr riscos e disposição para procurar oportunidades para inovar ou melhorar). Os três primeiros associam-se para formar a confiabilidade de uma pessoa; os outros três, para determinar o grau de disposição em entrar ou estar em relações confiantes. Na equipe Beta, observou-se mais os três primeiros ingredientes. A equipe Alfa diferenciou-se pelo exercício dos três últimos.

Analisando-se os dados segundo os estágios de desenvolvimento de equipe (Robbins \& Finley, 1997; Scholtes, 1992), observou-se que a equipe Alfa passou pelo estágio de formação, a partir da entrada do gerente AA - procuraram conhecer o novo gerente e ajustar o funcionamento como grupo; de tormenta enfrentaram alguns embates e discussões sobre o funcionamento do grupo, pressionado para entregar os resultados, em função do cronograma e das alterações gerenciais ocorridas no momento 1 e 2, antes da entrada do gerente AA; e aquiescência - conseguiram estabelecer algumas normas adequadas para um melhor funcionamento do grupo. Na época da coleta de dados desta pesquisa, seu comportamento era característico do estágio de realização: compreensão dos pontos fortes e fracos uns dos outros, os papéis estavam clarificados, havia análise contínua do desempenho individual e grupal, o trabalho deslanchava, os desacordos eram resolvidos, prazos eram cumpridos, fluíam as informações, o trabalho estava organizado e a atmosfera era de humor, entusiasmo e compromisso. A equipe era coesa e eficaz e seus membros a caracterizaram como de excelente desempenho. Foram explicitados os compromissos para atingimento das metas e os resultados alcançados como evidências de sucesso. Segundo declarações de AF, "Quando há confiança se ganha tempo e não há retrabalho". AB complementa, afirmando "Temos prazer em trabalhar".

Já na Equipe Beta, observou-se alianças no nível pessoal e não grupal, os integrantes não conversavam sobre suas dificuldades de relacionamento e havia falta de estabelecimento de condutas que norteassem a ação da equipe. A produtividade era baixa, segundo a avaliação do presidente da empresa. Pôde-se concluir que a equipe Beta, pelos dados levantados, se posicionou na fase de formação. No estágio de formação inicia-se a formação de uma relação de confiança, o que não foi percebido na equipe Beta, segundo afirmações de alguns de seus membros: "Alguns da equipe não são confiáveis" (BD). "BC não é um profissional competente para uma obra deste tamanho e não sabe comandar" (BA). "A passagem de informações, às vezes ocorre, mas na maioria fora do prazo" (BB).

Em relação à categorização de Katzenbach e Smith (2001), utilizando os conceitos da curva de performance, observou-se que a equipe Alfa era uma equipe real rumo à alta performance, enquanto a equipe Beta situava-se na curva de performance entre grupo de trabalho e equipe potencial: metas comuns existiam, mas faltava compartilhamento de informações e de melhores práticas, e não havia decisões conjuntas. A equipe Alfa apresentou um nível de desempenho acima do esperado, tendo superado as metas propostas, segundo as declarações do presidente e dados coletados na empresa. O lucro contratual da obra que era de 4,0\%, passou a ser de 7,0\% e o realizado estava próximo a 15,0\%. Já a equipe Beta apresentou baixo desempenho, estava aquém das metas e, segundo o presidente, gerando prejuízos. Essa performance foi confirmada pela empresa contratante, por meio da avaliação do grau de satisfação dos clientes, aplicada pela Tessália, três vezes ao ano. O contratante avaliou o desempenho da equipe Alfa como ótimo (100\%). Já o desempenho da equipe Beta, foi avaliada pelo contratante ótimo $(50 \%)$, bom $(40 \%)$ e regular $(10 \%)$. Para a equipe Alfa tornar-se uma equipe de alta performance seria ainda necessário que os membros da equipe estivessem devidamente compromissados com o crescimento uns dos outros e atendessem ou excedessem às expectativas.

\section{Considerações Finais}

O problema de investigação deste artigo consistiu em verificar a relação entre confiança e o desempenho de equipes. Dois foram os temas centrais destacados: confiança e equipe. Em confiança, optou-se por utilizar os conceitos de confiança transacional e transformadora, de dependência e interdependência, de componentes e disposições necessárias para se ter credibilidade. Em equipe, foram 
abordados os conceitos de diferenciação entre grupo e equipe, e de estágios de desenvolvimento de uma equipe.

Buscou-se estabelecer uma relação entre os conceitos de confiança e equipes. A confiança transformadora está interligada com a forma relacional de interdependência profunda e com as disposições das pessoas em investir nas relações, analisar os posicionamentos e correr riscos. As atitudes, posturas e condutas nesse nível são equivalentes ao estágio de realização e às equipes reais e de alta performance. A confiança transacional está relacionada com as outras formas relacionais, com os componentes de consistência, compromisso e capacidade e esses conceitos se equiparam com os estágios de formação, tormenta e aquiescência e com grupos de trabalho, pseudoequipes e equipes potenciais.

Nesta pesquisa, comparou-se a atuação de duas equipes de uma empresa do setor de construção civil, que operavam por projetos. As equipes selecionadas encontravam-se em situação análogas, segundo os critérios - nível organizacional, número de participantes e tempo de relacionamento, mas apresentavam diferença de desempenho - uma de alto desempenho, denominada Alfa, que estava superando as metas definidas pela empresa, e outra de baixo desempenho, denominada Beta, que não estava conseguindo alcançar suas metas. A comparação entre as duas equipes possibilitou verificar como a confiança se relaciona desempenho de equipes.

Os resultados deste estudo indicaram que a equipe de mais alto desempenho apresentou confiança transacional e transformadora entre seus membros, o que foi essencial para que ela conseguisse alcançar o alto desempenho. Já na equipe com baixo desempenho, os comportamentos relativos à confiança transacional indicaram a existência de problemas que se manifestaram negativamente na construção da confiança transformadora, refletidos no baixo desempenho.

Em relação à confiança transacional contratual, pôde-se observar que na equipe Alfa havia conhecimento mútuo das expectativas, as responsabilidades e parâmetros do trabalho estavam claros e eram seguidos e havia delegação; as metas e os compromissos eram cumpridos, observando-se a manifestação de ajuda mútua. Já na equipe Beta, as expectativas eram pouco explicitadas; apesar de as responsabilidades estarem claras no papel, na prática havia conflitos e a delegação era insuficiente.

Quanto à confiança transacional de comunicação, na equipe Alfa, observou-se um sistema de informação sistematizado, comunicação fluída e construtiva entre os participantes. Na equipe Beta, o sistema de informação era falho, tornando-se difícil agir como uma verdadeira equipe; não foi percebida a prática de dar e receber feedback, apesar de ter sido manifestada receptividade, caso ele ocorresse.

Referente à confiança transacional de competência, verificou-se que na equipe Alfa os conhecimentos e habilidades eram valorizados, as pessoas eram induzidas a decidir e assumir mais responsabilidades e a diversidade de opiniões era respeitada e valorizada. Por outro lado, nem todos da equipe Beta tinham sua capacidade explorada devidamente ou tinham permissão para tomar as decisões relativas ao seu trabalho, sendo que as contribuições de todos não eram habitualmente buscadas.

No que se refere à confiança transformadora, a equipe Alfa explicitou atitudes, posturas e disposições referentes aos fatores de convicção, coragem, compaixão e coletividade, fatores esses não evidenciados na equipe Beta.

Verificando as condutas das equipes, tendo como referência a confiança transacional e transformadora e comparando-as com as formas relacionais de dependência, pôde-se perceber que a equipe Alfa estava em uma relação de interdependência profunda, com condutas positivas em todas as outras formas relacionais. Já a equipe Beta apresentava condutas inadequadas e estava em uma relação entre dependência superficial e dependência profunda.

No que se refere aos estágios de desenvolvimento de equipes, a equipe Alfa manifestou condutas inerentes à fase de realização: os papéis estavam clarificados, havia análise contínua do desempenho individual e grupal, os desacordos eram resolvidos, os prazos eram cumpridos, as informações fluíam, a atmosfera era de alegria e entusiasmo e o desempenho era alto. Seu desempenho superou as metas estabelecidas pela empresa, sendo confirmado pelo grau de satisfação da empresa contratante. A equipe Beta se comportava dentro dos parâmetros da fase de formação. Ocorriam alianças no nível pessoal e não grupal, não eram estabelecidas condutas que norteassem a ação da equipe, com pouca evidência de comportamentos de confiança. Seu desempenho foi considerado baixo, tanto pela Tessália como pela empresa contratante. 
A equipe Alfa, com relação à curva de performance, era uma equipe real rumo à alta performance. Para atingir esse ponto, ela precisava desenvolver ações que manifestasse estar profundamente compromissada com o crescimento uns dos outros e que pudesse atender e exceder as expectativas de seus participantes. A equipe Beta se situava entre grupo de trabalho e equipe potencial. O grupo sentia necessidade de melhoria significativa do desempenho e de sua transformação em equipe; metas comuns existiam, mas faltava compartilhamento de informações, melhores práticas e decisões conjuntas.

Portanto, os resultados da pesquisa demonstraram que a equipe Alfa, que demonstrou comportamentos relativos à confiança transacional e transformadora, encontrava-se no estágio de realização, quanto ao desenvolvimento de equipe; de relação de interdependência profunda, quanto às formas relacionais; apresentava disposição para desenvolver-se, correr riscos, inovar e melhorar; e alto desempenho, mensurado em termos do atingimento das metas propostas. Em contrapartida, a equipe Beta, que apresentou comportamentos mais relacionados à confiança transacional, encontrava-se no estágio de formação; de dependência superficial e profunda; apresentava disposição para consistência, compromisso e capacidade; e baixo desempenho.

Essa pesquisa indica, assim, a confiança se relaciona com o desempenho de equipes de trabalho. Entretanto apresenta limitações, uma vez que foi realizado um único estudo de caso, com a análise de duas equipes em uma única empresa do setor de construção civil. Apesar dos resultados não poderem ser generalizados para outras empresas, os construtos teóricos poderão ser testados em outras realidades organizacionais, setoriais e culturais.

Este estudo avança ao conseguir mostrar que os conceitos de confiança podem ser utilizados juntamente com os de desenvolvimento e de curva de performance de equipe para compreender a dinâmica do trabalho em equipes de alto desempenho. Em termos acadêmicos, espera-se que este estudo seja uma contribuição para a construção teórica sobre os componentes constitutivos da confiança em equipes. Sugere-se que novos estudos sejam realizados em empresas de outros setores e em mais empresas simultaneamente, para fins de comparação. Sugere-se ainda a utilização de metodologias quantitativas, com a construção de uma escala que possibilite confirmar a relação entre as categorias propostas. O tema é desafiador, o campo é fecundo e outras pesquisas poderão contribuir para a sua consolidação nos estudos em administração.

\section{Notas}

1- Agradecemos à Prof. Jacquelaine Florindo Borges, Editora da Seção de Comportamento Organizational, pelo criterioso trabalho de revisão realizado no artigo.

\section{Referências}

Bennis, W.; Nanus, B. (1998). Líderes: estratégias para assumir a verdadeira liderança. São Paulo: Harbra.

Biehl, K. A. Grupos e equipes de trabalho: uma estratégia de gestão. In: Bitencourt, C. (Org.). (2004). Gestão contemporânea de pessoas. novas práticas, conceitos tradicionais. Porto Alegre: Bookman, p.133143.

Child, J. (2001). Trust - The Fundamental Bond in Global Collaboration. Organizational Dynamics, v.29, n.4, p.274-288.

Child, J., Rodrigues, S. B. (2004). Repairing de Breach of Trust in Corporate Governance. Corporate Governance: An International Review. v. 12, n.2, p.143-152.

Collis, J.; Hussey, R. (2005). Pesquisa em administração: um guia prático para alunos de graduação e pósgraduação. 2. ed. Porto Alegre: Bookman.

Comte-Sponville, A. (1995). Pequeno tratado das grandes virtudes. São Paulo: Martins Fontes.

Dias, H.B. P. D. (2010). Liderança, confiança e desempenho percebido. 175 p. Dissertação (Mestrado em Gestão). Faculdade de Economia, Universidade de Coimbra. Coimbra.

Drumond, V. S. (2007). Confiança e liderança nas organizações. São Paulo: Thomson Learning.

Duhá, A. H. (2007). Organizações de equipes efetivas: variáveis, processos e estratégias de investigação. 2007. 98f. Tese (Doutorado em Psicologia) - Programa de Pós-Graduação da Faculdade de Psicologia, Pontifícia Universidade Católica do Rio Grande do Sul. Porto Alegre. 
Duluc, A. (2000). Liderança e confiança: desenvolver o capital humano para organizações competitivas. Lisboa: Instituto Piaget.

Fukuyama, F. (1996). Confiança: as virtudes sociais e a criação da prosperidade. Rio de Janeiro: Ed. Rocco. Giddens, A. (1991). As conseqüências da modernidade. São Paulo: UNESP.

Hacker, S. K.; Willard, M. L. (2002). The trust imperative: performance improvement through productive relationships. Milwaukee: ASQ.

Ivancevich, J. M. (2008). Gestão de recursos humanos. São Paulo: McGraw-Hill.

Janowicz, M., Noorderhaven, N. (2002). The Role of Trust in Interorganizational Learning Joint Ventures Center, v.119.

Janowicz, M., Noorderhaven, N. (2009). Trust, calculation and interorganizational learning of tacit knowledge: An organizational roles perspective. Organization Studies, v. 30, n. 10, p.1021-1044.

Katzenbach, J. R. (2001). Equipes campeãs: desenvolvendo o verdadeiro potencial de equipes e líderes. Rio de Janeiro: Campus.

Katzenbach, J. R.; Smith, D. K. (1994). A força e o poder das equipes. São Paulo: Makron Books.

Katzenbach, J. R.; Smith, D. K. (2001). Equipes de alta performance: conceitos, princípios e técnicas para potencializar o desempenho das equipes. Rio de Janeiro: Campus.

Kotter, J. P. (1997). Liderando mudança. 13.ed. Rio de Janeiro: Elsevier.

Kraemer, R.M., Tyler, T. R. (eds.). (1996). Trust in organizations. Frontiers of theory and research. Thousand Oaks, CA: Sage.

Lane, C. (1996). Theories and issues in the study of trust. In: Lane, C.; Bachamann, R. (orgs.) Trust within and between organizations: compectual issues and empirical applications. New York: Oxford Uiversity Press Inc.

Lane, C., Bachmann, R. (orgs). (1997). Trust Within and between Organizations. Oxford: Oxford University Press.

Leana, C. R.; Burren, H.J.V. (1999). Organizational Social Capital and Employment Practices. Academy of Management Review, v.24, n.3, 539-555.

Lewicki, R.; Bunker, B. B. Developing and maintaining trust in work relationships. In: Kramer, R. M.; Tyler, T. R. (1996). Trust in organizations: frontiers of theory and research. Thousand Oaks: Sage Pub.

Luhmann, N. (1979). Trust and power. Chichester: Wiley.

Mandelli, P. (2001). Muito além da hierarquia: revolucione sua performance como gestor de pessoas. São Paulo: Gente.

Marras, J. P. (2000). Administração de Recursos Humanos: do operacional ao estratégico. 3ạ. Ed. São Paulo: Futura.

Mey, W. A.; Lima, M. R. S. (2002). Os fatores dificultadores e os fatores facilitadores na implementação e consolidação do modelo de trabalho por equipes autogerenciadas (EAGs). Anais do ENANPAD, XXVI, Salvador. (1CD ROM)

Möllering, G. (2001). The Nature of Trust: From Georg Simmel to a Theory of Expectation, Interpretation and Suspension. Sociology. v. 35, n. 2, p.403-420.

Moscovici, F. (1985). Desenvolvimento interpessoal. 3.ed. Rio de Janeiro: LTC.

Novelli, J. G. N. (2004). Confiança interpessoal na sociedade de consumo: a perspectiva gerencial. 228 f. 2004. Tese (Doutorado em Administração). Universidade de São Paulo, São Paulo.

Reina, D. S.; Reina, M. L. (2006). Trust and betrayal in the workplace: building effective relationships in your organization. San Francisco: Berrett-Koelher Pub.

Robbins, H.; Finley, M. (1997). Por que as equipes não funcionam. 4.ed. Rio de Janeiro: Campus.

Rosseau, D. M. et al. (1998). Not so different after all: a cross-discipline view of trust. Academy of Management Review, New York, v.23, n.3p. 393-404.

Schein, E. (1977). Consultoria de procedimentos: seu papel no Desenvolvimento Organizacional. São Paulo: Edgard Blucher.

Scholtes, P. R. (1992). Times da qualidade: como usar equipes para melhorar a qualidade. Rio de Janeiro: Qualitymark. 
Sheppard, B. H.; Sherman, D. M. (1998). The grammars of trust: a model and general implications. Academy of Management Review, v.23, n.3.

Tsai, W., Ghoshal, S. (1998). Social Capital and Value Creation: the role of intrafirm networks. Academy of Management Journal, v.41, n.4, 464-476.

Tzafrir, S.S.; Harel G.H. (2002). Trust-me: a scale form measuring manager employer trustworthiness. Academy of Management Review, Missisippi State.

Vergara, S. C. (2004). Projetos e relatórios de pesquisa em Administração. 4.ed. São Paulo: Atlas.

Yin, R. K. (2005). Estudo de caso: planejamento e métodos. 3.ed. Porto Alegre: Bookman.

Zand, E.E. (1972). Trust and managerial problem solving. Administrative Science Quarterly, v.17, n.2, p.229-239.

Zanini, M.T. (2007). Confiança: o principal ativo intangível de uma empresa. Rio de Janeiro: Elsevier. 